\title{
PENGARUH LINGKUNGAN KERJA, ROLE STRESS, DAN KOMPENSASI FINANSIAL PADA KEPUASAN KERJA DI HOTEL DEKUTA BALI
}

\author{
Ida Bagus Budi Utama ${ }^{1}$ \\ Ida Bagus Ketut Surya ${ }^{2}$
}

\author{
${ }^{1,2}$ Fakultas Ekonomi dan Bisnis Universitas Udayana (Unud), Bali, Indonesia \\ email: gusbudiutama@yahoo.co.id
}

\begin{abstract}
ABSTRAK
Tujuan penelitian ini adalah untuk menjelaskan mengenai pengaruh lingkungan kerja, role stress, dan kompensasi finansial pada kepuasan kerja karyawan. Populasi penelitian ini adalah seluruh karyawan Dekuta Hotel. Teknik pengambilan sampel dalam penelitian ini menggunakan sampel jenuh, sehingga diperoleh jumlah sampel sebanyak 52 orang karyawan. Metode pengumpulan data menggunakan kuisioner. Teknik analisis yang digunakan adalah analisis regresi linier berganda. Hasil penelitian ini menunjukkan bahwa lingkungan kerja dan kompensasi finansial berpengaruh positif dan signifikan terhadap kepuasan kerja. Hal ini berarti bahwa semakin baik lingkungan kerja dan semakin tinggi kompensasi finansial yang diberikan terhadap karyawan di Dekuta Hotel, maka akan membentuk kepuasan kerja yang semakin tinggi. Sedangkan variabel role stres berpengaruh negatif dan signifikan terhadap kepuasan kerja. Hal ini berarti bahwa semakin rendah role stres yang dialami karyawan Dekuta Hotel, maka akan semakin meningkatkan kepuasan kerja karyawan.
\end{abstract}

Kata Kunci: lingkungan kerja, role stress, kompensasi finansial, kepuasan kerja

\begin{abstract}
The purpose of this study is to explain the influence of the work environment, role stress, and financial compensation on employee job satisfaction. The population of this research is all employees of Dekuta Hotel. The sampling technique in this study used saturated samples, so that the number of samples obtained was 52 employees. Methods of collecting data using questionnaires. The analysis technique used is multiple linear regression analysis. The results of this study indicate that the work environment and financial compensation have a positive and significant effect on job satisfaction. This means that the better the work environment and the higher the financial compensation given to employees at the Dekuta Hotel, the higher the job satisfaction will be. While role stress variables have a negative and significant effect on job satisfaction. This means that the lower the role stress experienced by Dekuta Hotel employees, the more it will increase employee job satisfaction. Keywords: work environment, role stress, financial compensation, job satisfaction
\end{abstract}

Keywords: work environment, role stress, financial compensation, job satisfaction 


\section{PENDAHULUAN}

Kepuasan kerja memegang peran penting bagi organisasi karena kepuasan kerja merupakan kriteria dalam menentukan keberhasilan organisasi dalam memenuhi kebutuhan para anggotanya. Karyawan yang puas dengan pekerjaan mereka cenderung lebih kreatif dan inovatif yang membantu bisnis untuk tumbuh, berkembang dan membawa perubahan positif sesuai dengan situasi pasar dan dengan demikian membuat organisasi mampu bersaing di tingkat internasional (Bushra, 2011) Usaha untuk meningkatkan kepuasan kerja karyawan, diantaranya dengan memperhatikan lingkungan kerja. Lingkungan kerja merupakan segala sesuatu yang ada disekitar para pekerja yang dapat mempengaruhi dirinya dalam menjalankan tugas-tugas yang dibebankan (John \& Soma, 2011)

Lingkungan kerja merupakan segala sesuatu yang ada di sekitar para pekerja dan yang dapat mempengaruhi dirinya dalam melakukan tugas - tugas yang dibebankan. Lingkungan kerja yang tidak kondusif dapat menimbulkan efek - efek negatif seperti semangat kerja yang rendah, tingkat absensi yang tinggi, tingkat kesalahan dalam melakukan pekerjaan yang tinggi, turn over yang tinggi dan lain sebagainya. Hal - hal ini jelaslah harus dihindari karena tidak menguntungkan perusahaan. Dengan terjadinya kepuasan karyawan terhadap lingkungan kerja diharapkan karyawan dapat lebih kooperatif dalam mencapai tujuan perusahaan.

Karyawan dalam menjalankan tugasnya dipengaruhi lingkungan kerja. Kondisi lingkungan kerja yang nyaman, aman dan mendukung akan membuat karyawan menjadi bersemangat dan bergairah dalam bekerja, dalam hal ini dapat memberi pengaruh positif pada kinerjanya. Adanya semangat dan gairah dalam bekerja karyawan cenderung akan merasa puas dalam bekerja. Sebaliknya, lingkungan kerja yang banyak menimbulkan risiko atau tidak nyaman, dan tidak mendukung dalam pelaksanaan tugas yang dibebankan akan menyebabkan merosotnya semangat dan gairah kerja, kemungkinan akan terjadi kesalahan dalam tugas, dan menurunnya produktivitas kerja (Ruchi \& Sunnider, 2014)

Lingkungan kerja yang baik merupakan salah satu kondisi kerja yang mendukung. Karyawan membutuhkan lingkungan kerja yang baik, selain untuk kenyamanan juga sebagai faktor pendukung dalam melaksanakan pekerjaannya. Hal ini dapat menimbulkan rasa puas pada diri karyawan karena banyak faktor yang mendukung dalam bekerja Pangestu dkk. (2017). Oleh karena itu keadaan maupun situasi yang ada di sekitar karyawan dalam bekerja harus dijaga sebaik mungkin supaya karyawan akan merasa nyaman dalam bekerja. Temuan penelitian Aghozo et al. (2017) dan Bhanu dan Babu (2018) juga menunjukkan bahwa lingkungan kerja fisik berpengaruh signifikan positif terhadap variabel kepuasan kerja pegawai. Penelitian serupa oleh Wirawan dan Sudharma (2015), Haedar dkk. (2015), Husni dkk. (2018) dan Sari (2018) menemukan hasil bahwa lingkungan kerja berpengaruh positif dan signifikan pada kepuasan kerja karyawan yang berarti semakin baik lingkungan kerja fisik, maka kepuasan kerja akan semakin meningkat. Namun hasil berbeda ditemukan oleh penelitian Setyani (2014) yang menyatakan bahwa lingkungan kerja tidak berpengaruh pada kepuasan kerja karyawan. 
Faktor lain yang dapat mempengaruhi kepuasan kerja karyawan yaitu stres. Stres adalah kondisi dinamik yang didalamnya seorang individu dikontrontasikan dengan suatu peluang, kendala, atau tuntutan yang dikaitkan dengan apa yang sangat diinginkan dan hasilnya dipresepsikan sebagai tifak pasti dan penting Ang et al. (2014) Robbins menyatakan bahwa role stress terjadi oleh adanya tuntutan peran yang berhubungan dengan tekanan yang diberikan kepada seseorang sebagai suatu fungsi dari peran tertentu yang dimainkan dalam organisasi itu (Robbins dan Judge, 2008).

Quarat et al. (2013) menyatakan bahwa konflik peran muncul karena adanya ketidaksesuaian antara pengharapan yang disampaikan pada individual didalam organisasi dengan orang lain didalam dan diluar organisasi. Teori peran menyatakan bahwa individu akan mengalami role conflict apabila ada dua tekanan atau lebih yang terjadi secara bersamaan yang ditujukan kepada seseorang, sehingga apabila individu tersebut mematuhi satu diantaranya akan mengalami kesulitan atau tidak mungkin mematuhi yang lainnya. Muhammad et al. (2016) dalam penelitiannya menyatakan bahwa tingkat stres merupakan salah satu faktor yang mempengaruhi tinggi rendahnya kepuasan kerja pada karyawan. Stres dapat menyebabkan ketidakpuasan, stres yang berkaitan dengan pekerjaan dapat menyebabkan ketidakpuasan yang terkait dengan pekerjaan. Penelitian yang dilakukan oleh Beehr et al. (2006) menemukan bahwa role stressor yang terdiri dari role ambiguity, role conflict, dan role overload berkaitan dengan ketidakpuasan. Penelitian yang dilakukan oleh Yozgat et al. (2013), Ang et al. (2014), Damian (2016) dan Elewa (2017) memperoleh hasil bahwa role stress berpengaruh negatif signifikan pada kepuasan kerja. Hal ini berarti stres kerja dalam organisasi dapat mengakibatkan efek negatif seperti efisiensi berkurang, penurunan kapasitas untuk melakukan, rasa menurunkan harga diri, depresi, rendahnya motivasi untuk bekerja, kurangnya inisiatif dan mengurangi minat dalam bekerja, meningkatkan kekakuan pemikiran, kurangnya sebuah perhatian bagi organisasi dan rekan-rekan dan hilangnya tanggung jawab. Namun hasil berbeda diperoleh Sormin dkk. (2017) yang dalam penelitiannya menemukan bahwa stres kerja berpengaruh positif dan signifikan pada kepuasan kerja.

Two Factor Theory yang dikemukakan oleh Herzberg (2009) yang menyatakan bahwa kepuasan kerja dan ketidakpuasan merupakan dua hal yang berbeda dan berdampak terhadap umpan balik karyawan kepada organisasi. Two Factor Theory menyatakan bahwa karakteristik pekerjaan dapat dibagi menjadi dua kelompok yaitu satisfies (motivators) dan dissatisfies. Menurut Rivai (2012) satisfies ialah faktor-faktor yang dibutuhkan sebagai sumber kepuasan kerja yang meliputi yang menarik/menantang, kesempatan berprestasi, memperoleh penghargaan dan promosi, terpenuhinya faktor tersebut akan menimbulkan kepuasan namun tidak terpenuhinya faktor ini tidak selalu mengakibatkan ketidakpuasan, sedangkan dissatisfies (hygiene factors) adalah faktor-faktor yang menjadi sumber ketidakpuasan yang meliputi gaji/upah, pengawasan, hubungan antar pribadi serta kondisi kerja dan status. Penelitian ini menggunakan kompensasi financial sebagai variable yang diduga memiliki pengaruh pada kepuasan kerja karyawan. 
Kompensasi merupakan salah satu strategi sumber daya manusia untuk menciptakan keselarasan kerja antara staf dengan pimpinan dalam mencapai tujuan dan sasaran yang telah ditetapkan. Kompensasi karyawan merujuk pada bentuk upah atau imbalan yang berlaku bagi karyawan dan muncul dari pekerjaan dimana ada dua cara pemberian kompensasi, yaitu pembayaran keuangan langsung dan tidak langsung. Herland dan Sariyathi (2018) menyatakan bahwa pada umumnya kompensasi finansial dibagi menjadi dua bagian, yaitu kompensasi finansial langsung (direct financial compensation) yang terdiri dari bayaran (pay) yang diperoleh seseorang dalam bentuk gaji, upah, bonus, dan kompensasi finansial tidak langsung (indirect financial compensation) yang disebut dengan tunjangan meliputi semua imbalan finansial yang tidak tercakup dalam kompensasi langsung. Penelitian yang dilakukan oleh Dewi et al. (2013), Hidayat (2015), Ricky et al. (2016), dan Artha (2017) menyatakan bahwa semakin tinggi kompensasi finansial yang diberikan kepada karyawan, maka kepuasan karyawan cenderung akan semakin meningkat. Namun hasil berbeda diperoleh dalam penelitian Handaru dkk. (2013) yang menemukan hasil bahwa kompensasi tidak berpengaruh signifikan pada kepuasan kerja karyawan.

Salah satu hotel yang ada di Bali yaitu Dekuta Hotel Bali karyawan yang bergerak di jasa pelayanan. Dekuta Hotel Bali memerlukan karyawan dengan dengan kinerja yang sangat baik dan loyalitas yang tinggi terhadap perusahaan, karena hal itu akan sangat berpengaruh terhadap profit dari Dekuta Hotel Bali. Ketatnya persaingan Hotel yang ada di Bali, mengharuskan Dekuta Hotel Bali untuk terus meningkatkan pelayanannya kepada pelanggan.

Jumlah karyawan yang dimiliki Dekuta Hotel Bali yakni 52 orang yang terdiri dari 38 orang karyawan tetap dan 14 karyawan kontrak. Adapun data karyawan yang ada adalah ditunjukan pada Tabel 1.

Tabel 1.

Data Karyawan Dekuta Hotel Bali

\begin{tabular}{clc}
\hline No & \multicolumn{1}{c}{ Bagian } & Jumlah Karyawan \\
\hline 1 & Departemen Front office & 6 \\
2 & Departemen Food \&Beverage & 9 \\
3 & Departemen Housekeeping & 8 \\
4 & Departemen Engineering \& Marketing & 15 \\
5 & Departemen Accounting & 5 \\
6 & Bagian Lain-lain & 9 \\
\hline Sumber $:$ Dekuta Hotel, 2018
\end{tabular}

Setiap karyawannya memiliki peranan yang sangat penting dalam produktivitas perusahaan. Pendayagunaan sumber daya manusia secara produktif pada Dekuta Hotel Bali, tentu saja akan memberikan dampak yang positif bagi perusahaan. Kepuasan kerja karyawan diduga menjadi masalah yang saat ini ada diperusahaan, hal ini didasarkan pada wawancara awal yang dilakukan pada atasan dan karyawan, yang menyatakan bahwa terdapat beberapa karyawan ingin mencari pekerjaan ditempat lainnya, karena kurangnya insentif yang diperoleh karyawan. Hal tersebut terbukti dengan tingkat turnover karyawan yang terjadi Dekuta Hotel Bali cukup tinggi yang didukung oleh data pada Tabel 2. 
Tabel 2.

Data Turnover Karyawan Dekuta Hotel Selama Tahun 2015- 2018

\begin{tabular}{cccccc}
\hline Tahun & $\begin{array}{c}\text { Jumlah } \\
\text { karyawan } \\
\text { tetap awal } \\
\text { tahun (orang) }\end{array}$ & $\begin{array}{c}\text { Jumlah } \\
\text { karyawan } \\
\text { tetap akhir } \\
\text { tahun (orang) }\end{array}$ & $\begin{array}{c}\text { Rata-rata } \\
\text { karyawan } \\
\text { tetap }\end{array}$ & $\begin{array}{c}\text { Karyawan } \\
\text { keluar } \\
\text { (orang) }\end{array}$ & $\begin{array}{c}\text { Karyawan } \\
\text { keluar (\%) }\end{array}$ \\
\hline 2015 & 64 & 58 & 61 & 6 & 9.37 \\
2016 & 58 & 56 & 57 & 2 & 3.45 \\
2017 & 56 & 55 & 55.5 & 1 & 1.78 \\
2018 & 55 & 52 & 53.5 & 3 & 5.45 \\
\hline Sumber:
\end{tabular}

Tabel 2. menunjukkan bahwa tingkat turnover karyawan yang terjadi Dekuta Hotel Bali selama tahun 2015 hingga 2018 cukup tinggi. Jumlah turnover karyawan tersebut melampaui batas maksimal yang ditetapkan Dekuta Hotel sehingga menarik untuk diteliti terkait permasalahan sumber daya manusianya. Dengan alasan tersebut maka penelitian ini dilakukan pada karyawan Dekuta Hotel.

Berdasarkan permasalahan yang telah diungkapkan serta ditemukan adanya hasil penelitian terdahulu yang tidak konsisten, maka tujuan penelitian ini adalah untuk menjelaskan mengenai pengaruh lingkungan kerja, role stress, dan kompensasi finansial pada kepuasan kerja karyawan.

Berdasarkan telaah dan kajian penelitian terdahulu, maka dapat disusun hipotesis sebagai berikut:

$\mathrm{H}_{1}$ : Lingkungan kerja berpengaruh positif pada kepuasan kerja karyawan

$\mathrm{H}_{2}$ : Role stress berpengaruh negatif terhadap kepuasan kerja karyawan

$\mathrm{H}_{3}$ : Kompensasi finansial berpengaruh positif terhadap kepuasan kerja

Berdasarkan kajian penelitian terdahulu dan hipotesis yang sudah dirumuskan, maka model konseptual dalam penelitian ini adalah sebagai berikut:

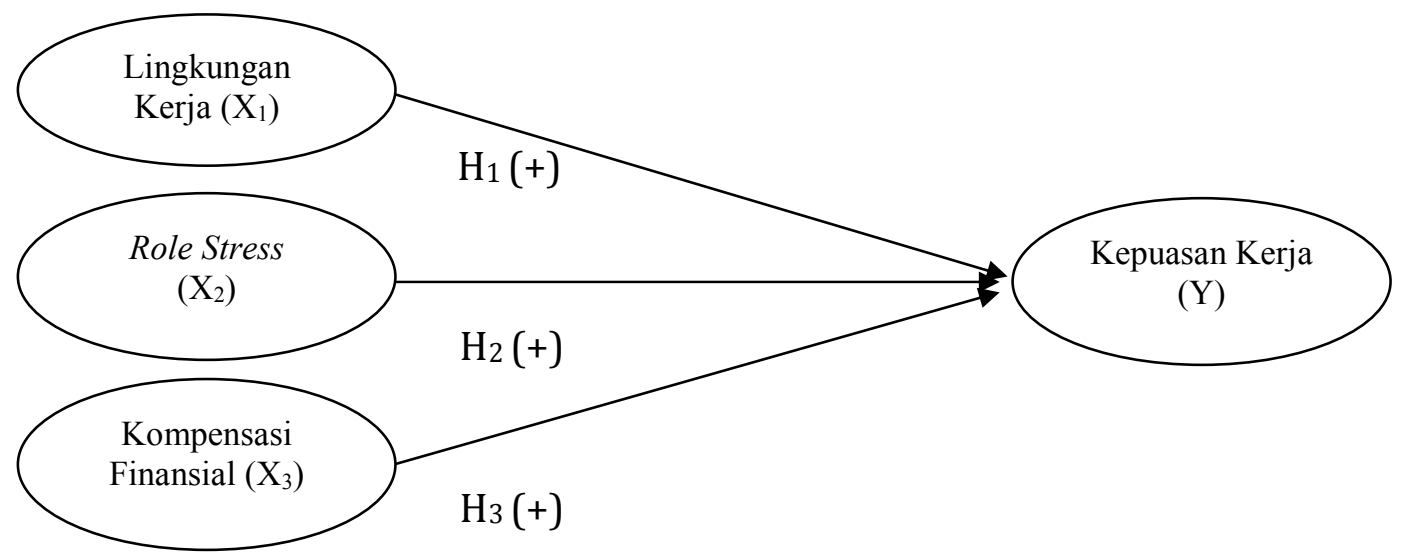

Gambar 1. Kerangka Konsep Penelitian 


\section{METODE PENELITIAN}

Pendekatan yang digunakan adalah pendekatan kuantitatif yang berbentuk asosiatif, yaitu pendekatan yang menunjukkan hubungan antara dua variabel atau lebih, hubungan dalam hal ini adalah antara variabel lingkungan kerja, role stress dan kompensasi finansial dengan kepuasan kerja karyawan. Lokasi penelitian adalah Dekuta Hotel yang berlokasi di Jln poppies 2, Kuta-Bali, Indonesia. Penelitian lokasi ini didasarkan pada beberapa pertimbangan masalah yang terkait dengan lingungan kerja, role stress dan kompensasi finansial terhadap kepuasan kerja karyawan.

Variabel yang digunakan dalam penelitian ini antara lain variabel bebas dan variabel terikat yang secara rinci dirangkum dalam Tabel 3.

\section{Tabel 3.}

Rangkuman Variabel dan Indikator Penelitian

\begin{tabular}{|c|c|c|c|}
\hline No & Variabel & Indikator & Sumber \\
\hline 1. & $\begin{array}{l}\text { Lingkungan Kerja } \\
\qquad\left(\mathrm{X}_{1}\right)\end{array}$ & $\begin{array}{l}\text { 1. Suasana kerja } \\
\text { 2. Hubungan dengan rekan kerja } \\
\text { 3. Tersedianya fasilitas kerja }\end{array}$ & Santoso (2018) \\
\hline 2. & $\begin{array}{c}\text { Stres Peran } \\
\text { (Tekanan Peran) } \\
\left(\mathrm{X}_{2}\right)\end{array}$ & $\begin{array}{l}\text { 1. Beban Kerja } \\
\text { 2. Tekanan } \\
\text { 3. Konflik } \\
\text { 1. Upah atau Gaji }\end{array}$ & $\begin{array}{l}\text { Yozgart et al., } \\
\qquad(2013)\end{array}$ \\
\hline 3. & $\begin{array}{l}\text { Kompensasi finansial } \\
\qquad\left(\mathrm{X}_{3}\right)\end{array}$ & $\begin{array}{l}\text { 2. Insentif } \\
\text { 3. Tunjangan } \\
\text { 4. Fasilitas }\end{array}$ & $\begin{array}{l}\text { Simamora } \\
(2006: 45)\end{array}$ \\
\hline 4. & $\begin{array}{c}\text { Kepuasan Kerja } \\
\text { (Y) }\end{array}$ & $\begin{array}{l}\text { 1. Pekerjaan itu sendiri (The work it self), } \\
\text { 2. Bayaran (Pay), } \\
\text { 3. Kesempatan mendapatkan promosi } \\
\text { jabatan (Promotion opportunities), } \\
\text { 4. Atasan (Supervisor), } \\
\text { 5. Rekan kerja (Co-workers) }\end{array}$ & $\begin{array}{l}\text { Cekmecelioglu } \\
\text { et al. (2012) }\end{array}$ \\
\hline
\end{tabular}

Sumber: Kajian penelitian sebelumnya, 2018

Populasi penelitian ini adalah seluruh karyawan Dekuta Hotel yaitu 52 karyawan. Sampel dalam penelitian ini adalah seluruh karyawan Dekuta Hotel. Penelitian ini menggunakan teknik pengambilan sampel jenuh. Menurut Sugiyono (2013) menyatakan bahwa teknik pengambilan sampel jenuh adalah teknik penentuan sampel bila semua anggota populasi digunakan sebagai sample.

Metode pengambilan data yang digunakan adalah kuesioner, wawancara dan observasi. Data kuisioner yang sudah terkumpul selanjutnya di tabulasi dan diuji kualitas datanya dengan uji validitas dan uji reliabilitas. Data yang sudah dinyatakan valid dan reliabel, kemudia di uji menggunakan uji prasyarat regresi, yakni uji asumsi klasik yang terdiri dari uji normalitas data, uji multikolinearitas, dan uji heteroskedastisitas.

Teknik analisis yang digunakan untuk menguji pengaruh lingkungan kerja, role stress dan kompensasi finansial terhadap kepuasan karyawan dalam penelitian ini menggunakan uji regresi linier berganda. Persamaan regresi linier berganda yang digunakan adalah sebagai berikut: 
$\mathrm{Y}=\alpha+\beta 1 \mathrm{X} 1+\beta 2 \mathrm{X} 2+\beta 3 \mathrm{X} 3+\mathrm{e}$

Dimana :

$$
\begin{array}{ll}
\mathrm{Y} & =\text { Kepuasan Karyawan } \\
\alpha & =\text { Konstanta } \\
\mathrm{X} 1 & =\text { Lingkungan Kerja } \\
\mathrm{X} 2 & =\text { Role Stress } \\
\mathrm{X} 3 & =\text { Kompensasi Finansial } \\
\beta 1-\beta 3 & =\text { Koefisien regresi } \\
\mathrm{e} & =\text { Error }
\end{array}
$$

\section{HASIL DAN PEMBAHASAN}

Karakteristik responden penelitian ini merupakan profil dari 52 responden

\begin{tabular}{|c|c|c|c|c|}
\hline No & Karakteristik & Klasifikasi & $\begin{array}{c}\text { Jumlah } \\
\text { Responden } \\
\text { (orang) }\end{array}$ & $\begin{array}{c}\text { Presentase } \\
\text { Responden } \\
(\%)\end{array}$ \\
\hline \multirow{4}{*}{1} & \multirow{2}{*}{ Jenis Kelamin } & Laki-Laki & 30 & 42,31 \\
\hline & & Perempuan & 22 & 57,69 \\
\hline & \multicolumn{2}{|c|}{ Jumlah } & 52 & 100 \\
\hline & \multirow{4}{*}{ Usia } & $17-24$ Tahun & 11 & 21,15 \\
\hline \multirow{5}{*}{2} & & 25 - 39 Tahun & 22 & 42,31 \\
\hline & & $40-50$ Tahun & 13 & 25,00 \\
\hline & & $>50$ Tahun & 6 & 11,54 \\
\hline & \multicolumn{2}{|c|}{ Jumlah } & 52 & 100 \\
\hline & & SLTA/SMA & 6 & 11,54 \\
\hline \multirow[t]{4}{*}{3} & Pendidikan & Diploma & 25 & 48,08 \\
\hline & Terakhir & Sarjana (S1) & 14 & 26,92 \\
\hline & & Pasca Sarjana (S2) & 7 & 13,46 \\
\hline & \multicolumn{2}{|c|}{ Jumlah } & 52 & 100 \\
\hline
\end{tabular}
yang berpartisipasi dalam pengisian kuesioner mengenai pengaruh variabel lingkungan kerja, role stress, dan kompensasi finansial pada kepuasan kerja karyawan Dekuta Hotel dapat dilihat dari beberapa kriteria yaitu: jenis kelamin, umur, dan pendidikan terakhir karyawan Dekuta Hotel dalam Tabel 4.

\section{Tabel 4.}

Karakteristik Responden Penelitian

Sumber: Data primer diolah, 2018

Tabel 4. menunjukkan mayoritas karyawan Dekuta Hotel adalah laki-laki. Kriteria responden berdasarkan usia menunjukkan bahwa karyawan di dominasi oleh responden yang berusia 25-39 tahun. Hal ini berarti bahwa Dekuta Hotel Bali sangat membutuhkan karyawan muda agar lebih giat dalam bekerja dan lebih bersemangat dalam bekerja. Dengan pegawai yang masih berusia muda juga akan membuat tamu merasa nyaman dilayani karyawan. Selanjutnya, apabila ditinjau berdasarkan jenjang pendidikan akhir responden menunjukkan mayoritas karyawan Dekuta Hotel Bali memiliki tingkat pendidikan akhir pada jenjang Diploma. Seseorang yang memiliki tingkat pendidikan Diploma diasumsikan 
memiliki pemahaman dan kemampuan yang baik karena sudah memiliki ilmu dan praktek kerja di bidang perhotelan.

Kualitas data dalam penelitian ini diuji dengan uji validitas dan reliabilitas yang disajikan dalam Tabel 5 sebagai berikut:

Tabel 5.

Rekapitulasi Hasil Uji Validitas dan Reliabilitas Instrumen Penelitian

\begin{tabular}{|c|c|c|c|c|}
\hline Variabel & Indikator & Koefisien Korelasi & Cronbach's Alpha & Keterangan \\
\hline \multirow{6}{*}{$\begin{array}{c}\text { Lingkungan } \\
\text { kerja }\left(X_{1}\right)\end{array}$} & $\mathrm{X}_{1.1}$ & 0,779 & \multirow{6}{*}{0,784} & Valid dan Reliabel \\
\hline & $\mathrm{X}_{1.2}$ & 0,750 & & Valid dan Reliabel \\
\hline & $\mathrm{X}_{1.3}$ & 0,778 & & Valid dan Reliabel \\
\hline & $\mathrm{X}_{14}$ & 0,756 & & Valid dan Reliabel \\
\hline & $\mathrm{X}_{1.5}$ & 0,744 & & Valid dan Reliabel \\
\hline & $\mathrm{X}_{1.6}$ & 0,598 & & Valid dan Reliabel \\
\hline \multirow{6}{*}{$\begin{array}{l}\text { Role stres } \\
\qquad\left(\mathrm{X}_{2}\right)\end{array}$} & $\mathrm{X}_{2.1}$ & 0,886 & \multirow{6}{*}{0,813} & Valid dan Reliabel \\
\hline & $\mathrm{X}_{2.2}$ & 0,905 & & Valid dan Reliabel \\
\hline & $\mathrm{X}_{2.3}$ & 0,868 & & Valid dan Reliabel \\
\hline & $\mathrm{X}_{2.4}$ & 0,872 & & Valid dan Reliabel \\
\hline & $\mathrm{X}_{2.5}$ & 0,929 & & Valid dan Reliabel \\
\hline & $\mathrm{X}_{2.6}$ & 0,848 & & Valid dan Reliabel \\
\hline \multirow{4}{*}{$\begin{array}{l}\text { Kompensasi } \\
\text { finansial }\left(\mathrm{X}_{3}\right)\end{array}$} & $\mathrm{X}_{3.1}$ & 0,805 & \multirow{4}{*}{0,815} & Valid dan Reliabel \\
\hline & $\mathrm{X}_{3.2}$ & 0,850 & & Valid dan Reliabel \\
\hline & $\mathrm{X}_{3.3}$ & 0,848 & & Valid dan Reliabel \\
\hline & $\mathrm{X}_{3.4}$ & 0,704 & & Valid dan Reliabel \\
\hline \multirow{5}{*}{$\begin{array}{l}\text { Kepuasan } \\
\text { Kerja (Y) }\end{array}$} & $\mathrm{Y}_{1}$ & 0,674 & \multirow{5}{*}{0,789} & Valid dan Reliabel \\
\hline & $Y_{2}$ & 0,794 & & Valid dan Reliabel \\
\hline & $\mathrm{Y}_{3}$ & 0,825 & & Valid dan Reliabel \\
\hline & $\mathrm{Y}_{4}$ & 0,631 & & Valid dan Reliabel \\
\hline & $\mathrm{Y}_{5}$ & 0,781 & & Valid dan Reliabel \\
\hline
\end{tabular}

Sumber : Data diolah, 2018

Hasil uji validitas pada Tabel 5. menunjukkan bahwa seluruh instrumen penelitian yang digunakan untuk mengukur variabel lingkungan kerja, role stres, kompensasi finansial dan kepuasan kerja memiliki nilai koefisien korelasi dengan skor total seluruh item pernyataan lebih besar dari 0,30 dan memiliki koefisien Cronbach's Alpha lebih dari 0,60. Hal ini menunjukkan bahwa butir-butir pernyataan dalam instrument penelitian tersebut valid dan reliabel, sehingga layak digunakan sebagai instrument penelitian.

Skor pada penelitian ini memiliki nilai tertinggi maksimal 5 dan terendah minimal 1, sehingga dapat disusun kriteria pengukuran sebagai berikut.

Kriteria pengukuran tersebut menunjukkan bahwa semakin tinggi nilai ratarata yang diperoleh menunjukkan semakin baik tanggapan responden terhadap item maupun variabel tersebut. 
Tabel 6.

Kriteria Skor Variabel Penelitian

\begin{tabular}{|c|c|c|c|c|}
\hline Nilai Skor & $\begin{array}{c}\text { Gaya } \\
\text { Kepemimpinan }\end{array}$ & Role stres & $\begin{array}{c}\text { Kompensasi } \\
\text { finansial }\end{array}$ & $\begin{array}{c}\text { Kepuasan } \\
\text { Kerja }\end{array}$ \\
\hline $1,00-1,80$ & $\begin{array}{c}\text { Sangat tidak } \\
\text { baik }\end{array}$ & Sangat rendah & Sangat rendah & Sangat tidak puas \\
\hline $1,81-2,61$ & Tidak baik & Rendah & Rendah & Tidak puas \\
\hline $2,62-3,42$ & Cukup Baik & Cukup Rendah & Cukup Rendah & Cukup Puas \\
\hline $3,43-4,23$ & Baik & Tinggi & Tinggi & Puas \\
\hline $4,24-5,00$ & Sangat baik & Sangat Tinggi & Sangat Tinggi & Sangat puas \\
\hline
\end{tabular}

Tabel 7.

Deskripsi Penilaian Responden Terhadap Lingkungan Kerja

\begin{tabular}{|c|c|c|c|c|c|c|c|}
\hline \multirow[t]{2}{*}{ Pernyataan } & \multicolumn{5}{|c|}{$\begin{array}{c}\text { Frekuensi Jawaban } \\
\text { Responden }\end{array}$} & \multirow[t]{2}{*}{ Rata-rata } & \multirow[t]{2}{*}{ Keterangar } \\
\hline & 1 & 2 & 3 & 4 & 5 & & \\
\hline $\begin{array}{l}\text { Penerangan lampu dalam } \\
\text { ruangan kerja saya sudah } \\
\text { memadai }\left(\mathrm{X}_{2.1}\right)\end{array}$ & 0 & 4 & 11 & 24 & 13 & 3.88 & Baik \\
\hline $\begin{array}{l}\text { Kebersihan di perusahaan } \\
\text { membuat saya nyaman dalam } \\
\text { bekerja }\left(\mathrm{X}_{2.2}\right)\end{array}$ & 0 & 3 & 11 & 25 & 13 & 3.92 & Baik \\
\hline \multicolumn{6}{|c|}{ Rata-Rata Indikator Suasana Kerja } & 3,90 & Baik \\
\hline $\begin{array}{l}\text { Hubungan saya dengan } \\
\text { pimpinan terjalin dengan baik } \\
\left(\mathrm{X}_{2.3}\right)\end{array}$ & 1 & 3 & 11 & 19 & 18 & 3.96 & Baik \\
\hline $\begin{array}{l}\text { Hubungan saya dengan sesama } \\
\text { karyawan terjalin dengan baik } \\
\left(\mathrm{X}_{2.4}\right)\end{array}$ & 0 & 4 & 15 & 20 & 13 & 3.81 & Baik \\
\hline \multicolumn{6}{|c|}{ Rata-Rata Indikator Rekan Kerja } & 3,86 & Baik \\
\hline $\begin{array}{l}\text { Perusahaan tempat saya } \\
\text { bekerja memberikan keamanan } \\
\text { lingkungan yang memadai } \\
\left(\mathrm{X}_{2.5}\right)\end{array}$ & 1 & 1 & 14 & 27 & 9 & 3.81 & Baik \\
\hline $\begin{array}{l}\text { Fasilitas yang disediakan oleh } \\
\text { perusahaan sudah memadai } \\
\text { untuk melaksanakan pekerjaan } \\
\left(\mathrm{X}_{2.6}\right)\end{array}$ & 1 & 3 & 16 & 18 & 14 & 3.79 & Baik \\
\hline \multicolumn{6}{|c|}{ Rata-Rata Indikator Fasilitas Kerja } & 3,80 & Baik \\
\hline \multicolumn{6}{|c|}{ Rata-rata Variabel Lingkungan Kerja } & 3,85 & Baik \\
\hline
\end{tabular}

Sumber: Data primer diolah, 2018

Hasil analisis deksriptif sebagaimana disajikan pada Tabel 7. menunjukkan skor rata-rata lingkungan kerja sebesar 3,85, yang berarti bahwa lingkungan kerja di Dekuta Hotel Bali dikatakan baik. Pencapaian nilai rata-rata diikuti oleh adanya indikator yang lebih tinggi dan lebih rendah dari rata-rata variabel lingkungan kerja. Indikator yang memperoleh penilaian tertinggi dari responden adalah indikator suasana kerja dengan nilai sebesar 3,90. Hal tersebut disebabkan karena karyawan merasa penerangan lampu dalam ruangan kerja sudah memadai dan kebersihan pada Dekuta Hotel Bali membuat karyawan saya nyaman dalam 
bekerja, sehingga membuat lingkungan kerja Dekuta Hotel menjadi baik dan nyaman.

Indikator yang memperoleh nilai rata-rata terendah adalah indikator fasilitas kerja dengan nilai sebesar 3,80. Fasilitas kerja Dekuta Hotel Bali sudah memperoleh penilaian yang baik dari karyawan berdasarkan hasil kuisioner, namun masih lebih rendah dari nilai rata-rata variabel lingkungan kerja. Hal ini disebabkan karena masih terdapat beberapa karyawan yang merasa bahwa Fasilitas yang disediakan oleh Dekuta Hotel kurang memadai untuk melaksanakan pekerjaan. Oleh karena itu, dalam upaya meningkatkan lingkungan kerja ke arah yang lebih baik, maka pihak manajemen Dekuta Hotel sebaiknya mengevaluasi dan meningkatkan kembali fasilitas yang menunjang pekerjaan karyawan.

Variabel role stres diukur dengan menggunakan 3 indikator yang dibuat dalam bentuk 6 item pernyataan yang berhubungan dengan role stres yang dirasakan oleh karyawan Dekuta Hotel Bali yang ditunjukan dalam Tabel 8 . sebagai berikut:

Tabel 8.

Deskripsi Penilaian Responden Terhadap Role stres

\begin{tabular}{|c|c|c|c|c|c|c|c|}
\hline \multirow[t]{2}{*}{ Pernyataan } & \multicolumn{5}{|c|}{$\begin{array}{c}\text { Frekuensi Jawaban } \\
\text { Responden }\end{array}$} & \multirow{2}{*}{$\begin{array}{l}\text { Rata- } \\
\text { rata }\end{array}$} & \multirow[t]{2}{*}{ Keterangan } \\
\hline & 1 & 2 & 3 & 4 & 5 & & \\
\hline $\begin{array}{l}\text { Saya merasa beban kerja yang } \\
\text { diberikan berlebihan }\left(\mathrm{X}_{2.1}\right)\end{array}$ & 1 & 14 & 15 & 15 & 7 & 3.25 & Cukup rendah \\
\hline $\begin{array}{l}\text { Saya merasa jadwal kerja yang } \\
\text { ditentukan melebihi jam kerja yang } \\
\text { ditentukan }\left(\mathrm{X}_{2.2}\right)\end{array}$ & 5 & 10 & 12 & 15 & 10 & 3.29 & Cukup rendah \\
\hline Rata-Rata Indikator Beban Kerja & & & & & & 3,27 & Cukup rendah \\
\hline $\begin{array}{l}\text { Saya merasa tertekan dengan tugas } \\
\text { yang diberikan atasan }\left(\mathrm{X}_{2.3}\right)\end{array}$ & 1 & 14 & 13 & 17 & 7 & 3.29 & Cukup rendah \\
\hline $\begin{array}{l}\text { Saya tertekan dengan deadline } \\
\text { pekerjaan yang diberikan atasan }\left(\mathrm{X}_{2.4}\right)\end{array}$ & 0 & 13 & 16 & 13 & 10 & 3.38 & Cukup rendah \\
\hline Rata-Rata Indikator Tekanan & & & & & & 3,34 & Cukup rendah \\
\hline $\begin{array}{l}\text { Saya merasa tidak didukung oleh } \\
\text { keluarga }\left(\mathrm{X}_{2.5}\right)\end{array}$ & 2 & 10 & 17 & 12 & 11 & 3.38 & Cukup rendah \\
\hline $\begin{array}{l}\text { Saya memiliki rekan kerja yang kurang } \\
\text { mendukung }\left(\mathrm{X}_{2.6}\right)\end{array}$ & 2 & 13 & 16 & 17 & 4 & 3.15 & Cukup rendah \\
\hline \multicolumn{6}{|l|}{ Rata-Rata Indikator Konflik } & 3,26 & Cukup rendah \\
\hline \multicolumn{6}{|c|}{ Rata-rata Variabel Role stres } & 3,29 & Cukup rendah \\
\hline
\end{tabular}

Sumber: Data primer diolah, 2018

Hasil analisis deksriptif sebagaimana disajikan pada Tabel 8. menunjukkan skor rata-rata role stres sebesar 3,29, yang berarti bahwa tingkat role stres karyawan Dekuta Hotel Bali cukup rendah. Pencapaian nilai rata-rata diikuti oleh adanya indikator yang lebih tinggi dan lebih rendah dari rata-rata variabel role stres. Indikator yang memperoleh nilai rata-rata terendah adalah indikator konflik dengan nilai sebesar 3,26. Fasilitas kerja Dekuta Hotel Bali sudah memperoleh penilaian yang baik dari karyawan berdasarkan hasil kuisioner, namun masih lebih rendah dari nilai rata-rata variabel role stres. Hal ini disebabkan karena masih terdapat beberapa karyawan yang merasa tidak didukung oleh keluarga dan 
memiliki rekan kerja yang kurang mendukung, sehingga membentuk tekanan stres pada karyawan.

Indikator yang memperoleh penilaian tertinggi dari responden adalah indikator tekanan dengan nilai sebesar 3,34. Hal tersebut disebabkan karena karyawan merasa tertekan dengan tugas yang diberikan atasan dan tertekan dengan deadline pekerjaan yang diberikan atasan Dekuta Hotel Bali. Oleh karena itu, dalam upaya meminimalisasi role stres ke arah yang lebih baik, maka atasan Dekuta Hotel sebaiknya memberi tugas dan deadline kepada karyawan sesuai dengan kemampuannya agar karyawan tidak merasa tertekan dengan tugasdan deadline yang diberikan.

Variabel kompensasi finansial diukur dengan menggunakan 4 item pernyataan yang berhubungan dengan kompensasi finansial yang dirasakan oleh karyawan Dekuta Hotel Bali. Data yang ditunjukan Tabel 9 menampilkan proporsi jawaban responden, rata-rata jawaban, dan kriteria penilaian jawaban responden untuk masing-masing pernyataan pada variabel kompensasi finansial

Tabel 9.

Deskripsi Penilaian Responden Terhadap Kompensasi finansial

\begin{tabular}{|c|c|c|c|c|c|c|c|}
\hline \multirow{2}{*}{ Pernyataan } & \multicolumn{5}{|c|}{ Frekuensi Jawaban Responden } & \multirow{2}{*}{$\begin{array}{c}\text { Rata- } \\
\text { rata }\end{array}$} & \multirow{2}{*}{ Keterangan } \\
\hline & 1 & 2 & 3 & 4 & 5 & & \\
\hline $\begin{array}{l}\text { Gaji atau upah yang karyawan } \\
\text { terima sesuai dengan beban } \\
\text { kerja }\left(\mathrm{X}_{3.1}\right)\end{array}$ & 0 & 1 & 8 & 31 & 12 & 4.04 & Tinggi \\
\hline $\begin{array}{l}\text { Jumlah insentif yang } \\
\text { diberikan perusahaan sesuai } \\
\text { dengan kinerja karyawan } \\
\left(\mathrm{X}_{3.2}\right)\end{array}$ & 1 & 1 & 12 & 21 & 17 & 4.00 & Tinggi \\
\hline $\begin{array}{l}\text { Jumlah tunjangan yang } \\
\text { diberikan sesuai dengan tugas } \\
\text { dan tanggung jawab }\left(\mathrm{X}_{3.3}\right)\end{array}$ & 1 & 3 & 22 & 20 & 6 & 3.52 & Tinggi \\
\hline $\begin{array}{l}\text { Fasilitas yang karyawan } \\
\text { terima sudah memadai sesuai } \\
\text { dengan pekerjaan }\left(\mathrm{X}_{3.4}\right)\end{array}$ & 0 & 2 & 10 & 27 & 13 & 3.98 & Tinggi \\
\hline \multicolumn{6}{|c|}{ Rata-rata Variabel Kompensasi finansial } & 3,88 & Tinggi \\
\hline
\end{tabular}

Hasil analisis deksriptif sebagaimana disajikan pada Tabel 9. menunjukkan skor rata-rata kompensasi finansial sebesar 3,88, yang berarti bahwa kompensasi finansial yang diberikan oleh Dekuta Hotel Bali sudah tinggi. Pencapaian nilai rata-rata diikuti oleh adanya indikator yang lebih tinggi dan lebih rendah dari ratarata variabel kompensasi finansial. Dari 4 indikator yang digunakan untuk mengukur kompensasi finansial, maka terdapat 3 indikator yang nilainya berada di atas nilai rata-rata $(3,88)$ variabel kompensasi finansial. Indikator gaji atau upah memiliki nilai paling tinggi jika dibandingkan dengan indikator lainnya. Hal tersebut disebabkan karena Dekuta Hotel Bali sudah memberikan gaji atau upah yang karyawan terima sesuai dengan beban kerja.

Indikator yang memperoleh nilai rata-rata terendah adalah indikator tunjangan dengan nilai rata-rata sebesar 3,52. Indikator tunjangan pada Dekuta Hotel Bali sudah memperoleh penilaian yang baik dari karyawan berdasarkan 
hasil kuisioner, namun masih lebih rendah dari nilai rata-rata variabel kompensasi finansial. Hal tersebut disebabkan karena masih terdapat beberapa karyawan yang merasa bahwa jumlah tunjangan yang diberikan kurang sesuai dengan tugas dan tanggung jawab. Oleh karena itu, dalam upaya meningkatkan kompensasi finansial menjadi lebih baik lagi, maka pihak manajemen Dekuta Hotel Bali diharapkan dapat memberikan jumlah tunjangan sesuai dengan tugas dan tanggung jawab masing-masing karyawan, sehingga karyawan merasa dihargai dan kepuasan kerja dapat terwujud.

Variabel kepuasan kerja diukur dengan menggunakan 5 item pernyataan yang berhubungan dengan kepuasan kerja karyawan Dekuta Hotel Bali. Data yang ditunjukan Tabel 10. menampilkan proporsi jawaban responden, rata-rata jawaban, dan kriteria penilaian jawaban responden untuk masing-masing pernyataan pada variabel kepuasan kerja.

Tabel 10.

Deskripsi Penilaian Responden Terhadap Kepuasan kerja

\begin{tabular}{|c|c|c|c|c|c|c|c|}
\hline \multirow[t]{2}{*}{ Pernyataan } & \multicolumn{5}{|c|}{$\begin{array}{c}\text { Frekuensi Jawaban } \\
\text { Responden }\end{array}$} & \multirow{2}{*}{$\begin{array}{c}\text { Rata- } \\
\text { rata }\end{array}$} & \multirow[t]{2}{*}{ Keterangan } \\
\hline & 1 & 2 & 3 & 4 & 5 & & \\
\hline $\begin{array}{l}\text { Saya diberikan kesempatan untuk } \\
\text { bertanggung jawab dengan pekerjaan }\left(\mathrm{Y}_{1}\right)\end{array}$ & 0 & 2 & 16 & 22 & 12 & 3.85 & Puas \\
\hline $\begin{array}{l}\text { Saya merasa gaji yang diberikan sudah } \\
\text { sesuai dengan beban kerja }\left(\mathrm{Y}_{2}\right)\end{array}$ & 0 & 2 & 10 & 22 & 18 & 4.08 & Puas \\
\hline $\begin{array}{l}\text { Saya merasa puas dengan kesempatan } \\
\text { yang diberikan untuk mengembangkan } \\
\text { karir saya. }\left(\mathrm{Y}_{3}\right)\end{array}$ & 1 & 2 & 14 & 20 & 15 & 3.88 & Puas \\
\hline $\begin{array}{l}\text { Atasan saya selalu memberikan saya } \\
\text { dukungan. }\left(\mathrm{Y}_{4}\right)\end{array}$ & 1 & 4 & 13 & 23 & 11 & 3.75 & Puas \\
\hline $\begin{array}{l}\text { Saya senang memiliki rekan kerja yang } \\
\text { saling mendukung }\left(\mathrm{Y}_{5}\right)\end{array}$ & 0 & 1 & 12 & 26 & 13 & 3.98 & Puas \\
\hline \multicolumn{6}{|c|}{ Rata-rata Variabel Kepuasan Kerja } & 3,91 & Puas \\
\hline
\end{tabular}

Sumber: Data primer diolah, 2018

Hasil analisis deksriptif sebagaimana disajikan pada Tabel 10. menunjukkan skor rata-rata kepuasan kerja sebesar 3,91, yang berarti bahwa karyawan sudah puas bekerja di Dekuta Hotel Bali. Indikator yang memperoleh nilai rata-rata terendah adalah indikator atasan (supervisor) dengan nilai rata-rata sebesar 3,75. Indikator ini sudah memperoleh penilaian yang baik dari karyawan berdasarkan hasil kuisioner, namun masih lebih rendah dari nilai rata-rata variabel kepuasan kerja. Hal tersebut disebabkan karena atasan atau pimpinan pada Dekuta Hotel Bali kurang memberikan dukungan pada karyawannya. Oleh karena itu, dalam upaya meningkatkan kepuasan kerja karyawan, maka pimpinan diharapkan dapat memberikan dukungan dan pengawasan yang baik kepada seluruh karyawan agar karyawan merasa diayomi, sehingga dapat meningkatkan kepuasan karyawan saat bekerja di Dekuta Hotel.

Model regresi akan lebih tepat digunakan dan menghasilkan perhitungan yang lebih akurat, apabila beberapa asumsi berikut dapat terpenuhi. Uji asumsi klasik yang harus dipenuhi pada analisis regresi linear sederhana antara lain Uji 
Normalitas, Uji Multikolinearitas dan Uji Heterokedastisitas yang dirangkum dalam Tabel 11. berikut ini:

Tabel 11.

Rangkuman Hasil Uji Asumsi Klasik

\begin{tabular}{|c|c|c|c|c|c|}
\hline \multirow{2}{*}{\multicolumn{2}{|c|}{ Hasil Uji Normalitas }} & \multirow[t]{2}{*}{ Variabel } & \multicolumn{2}{|c|}{$\begin{array}{c}\text { Hasil Uji } \\
\text { Multikolinieritas }\end{array}$} & \multirow{2}{*}{$\begin{array}{c}\text { Hasil Uji } \\
\text { Heteroskedastisitas } \\
\text { Signifikansi } \\
\end{array}$} \\
\hline & & & Tolerance & VIF & \\
\hline $\mathrm{N}$ & 52 & $\begin{array}{l}\text { Lingkungan kerja } \\
\left(\mathrm{X}_{1}\right)\end{array}$ & 0,774 & 1,292 & 0,936 \\
\hline $\begin{array}{l}\text { Kolmogorov- } \\
\text { Smirnov Z }\end{array}$ & 0,737 & $\begin{array}{c}\text { Role stres } \\
\left(\mathrm{X}_{2}\right)\end{array}$ & 0,981 & 1,020 & 0,154 \\
\hline $\begin{array}{l}\text { Asymp.Sig. (2- } \\
\text { tailed) }\end{array}$ & 0,648 & $\begin{array}{c}\text { Kompensasi finansial } \\
\left(\mathrm{X}_{3}\right)\end{array}$ & 0,786 & 1,272 & 0,381 \\
\hline
\end{tabular}

Sumber: Data diolah, 2018

Berdasarkan uraian pada Tabel 11, menunjukkan bahwa data sudah berdistribusi normal karena memiliki nilai signifikansi sebesar 0,624 $>0,05$, kemudian nilai tolerance lebih besar dari $10 \%$ dan nilai VIF lebih kecil dari 10 yang berarti model persamaan regresi bebas dari multikolinearitas. Selanjutnya hasil menunjukkan nilai Signifikansi dari variabel lingkungan kerja, role stres, dan kompensasi finansial masing-masing sebesar 0,936; 0,154 dan 0,381 yang lebih besar dari 0,05, sehingga disimpulkan semua asumsi klasik sudah terpenuhi, maka selanjutnya memaparkan hasil analisis regresi linier berganda seperti yang ditunjukan pada Tabel 12.

Tabel 12.

Hasil Analisis Regresi Linier Berganda

\begin{tabular}{lcccc}
\hline \multicolumn{1}{c}{ Variabel } & Unstandardized Beta & Std. Error & t hitung & Sig. uji t \\
\hline (Constant) & 8,790 & 2,743 & 3,204 & 0,002 \\
Lingkungan kerja $\left(\mathrm{X}_{1}\right)$ & 0,338 & 0,096 & 3,504 & 0,001 \\
Role stres $\left(\mathrm{X}_{2}\right)$ & $-0,131$ & 0,058 & $-2,262$ & 0,028 \\
Kompensasi finansial $\left(\mathrm{X}_{3}\right)$ & 0,354 & 0,146 & 2,428 & 0,019 \\
R Square & 0,467 & & & \\
F Statistik & 14,004 & & & \\
Signifikansi Uji F & 0,000 & & & \\
\hline
\end{tabular}

Sumber : Data primer diolah, 2018

Hasil uji koefisien determinasi pada Tabel 12. menunjukkan nilai R Square sebesar 0,467 mempunyai arti bahwa sebesar 46,7\% variasi kepuasan kerja karyawan dipengaruhi oleh variasi lingkungan kerja, role stres, dan kompensasi finansial, sedangkan sisanya sebesar 53,3\% dijelaskan oleh faktor lain yang tidak dimasukkan ke dalam model.

Tabel 12. menunjukkan nilai $F_{h i t u n g}$ sebesar 14,004 dengan signifkansi sebesar 0,000. Sedangkan $F_{\text {tabel }}$ pada Lampiran 10 adalah sebesar 2,78. Oleh karena nilai $F_{\text {hitung }}>F_{\text {tabel }}, 14,004>2,78$, dengan nilai sig. $0,000<0,05$, maka Ho ditolak dan $\mathrm{H}_{1}$ diterima. Kesimpulannya, pada kelompok yang diuji memiliki 
perbedaan yang nyata (signifikan). Hasil ini mempunyai arti bahwa secara simultan lingkungan kerja, role stres, dan kompensasi finansial berpengaruh signifikan terhadap kepuasan kerja karyawan Dekuta Hotel Bali.

Berdasarkan hasil analisis pengaruh lingkungan kerja terhadap kepuasan kerja pada Tabel 12. diperoleh nilai signifikasi sebesar 0,001 dengan nilai koefisien regresi positif sebesar 0,338. Nilai Signifikansi 0,001 $<0,05$ mengindikasikan bahwa $\mathrm{H}_{0}$ ditolak dan $\mathrm{H}_{1}$ diterima. Hasil ini mempunyai arti bahwa lingkungan kerja berpengaruh positif dan signifikan terhadap kepuasan kerja karyawan Dekuta Hotel Bali. Hal ini memiliki makna bahwa semakin baik lingkungan kerja di Dekuta Hotel, maka akan semakin tinggi pula kepuasan kerja yang terbentuk pada karyawan. Begitu pula sebaliknya, semakin buruk lingkungan kerja di Dekuta Hotel maka semakin rendah tingkat kepuasan kerja karyawan pada Dekuta Hotel.

Hasil tersebut mengindikasikan bahwa nilai - nilai yang terkandung dalam lingkungan kerja mampu dipersepsikan dengan baik dan berdampak nyata terhadap kepuasan kerja karyawan Dekuta Hotel. Lingkungan kerja yang diukur berdasarkan indikator: suasana kerja, hubungan dengan rekan kerja dan tersedianya fasilitas kerja terbukti mampu meningkatkan kepuasan kerja karyawan Dekuta Hotel. Temuan ini dapat diartikan bahwa apabila Dekuta Hotel memiliki suasana kerja yang nyaman, terdapat hubungan yang harmonis dan akrab diantara karyawan serta tersedianya fasilitas kerja yang memadai, maka hal tersebut mampu memberikan kontribusi yang signifikan untuk meningkatkan kepuasan kerja karyawan.

Hasil penelitian ini sesuai dengan hasil penelitian Aruan dan Fakhri (2015) menyimpulkan bahwa lingkungan kerja secara parsial dan simultan berpengaruh positif dan signifikan terhadap kepuasan kerja karyawan yaitu semakin baik lingkungan kerja maka semakin tinggi kepuasan kerja karyawan. Lingkungan kerja yang baik meliputi hubungan dengan karyawan yang terjalin baik, peraturan yang dijalankan dengan baik, sirkulasi udara yang baik dan keamanan lingkungan kerja yang terjaga akan membuat karyawan merasa tenang dan nyaman sehingga kepuasan kerja akan meningkat. Hasil penelitian ini juga mendukung temuan penelitian Haedar dkk. (2015), Wirawan dan Sudharma (2015), Putri (2016), Husni dkk. (2018), Sari (2018) dan Santoso (2018) yang menemukan hasil bahwa lingkungan kerja berpengaruh positif dan signifikan pada kepuasan kerja karyawan yang berarti semakin baik kondisi lingkungan kerja maka akan berpengaruh pada semakin meningkatnya kepuasan kerja karyawan.

Berdasarkan hasil analisis pengaruh role stres terhadap kepuasan kerja pada Tabel 12. diperoleh nilai signifikansi sebesar 0,028 dengan nilai koefisien regresi yang negatif sebesar -0,131. Nilai Signifikansi $0,028<0,050$, maka mengindikasikan bahwa $\mathrm{H}_{0}$ ditolak dan $\mathrm{H}_{2}$ diterima. Hasil ini mempunyai arti bahwa Role stres berpengaruh negatif dan signifikan terhadap kepuasan kerja karyawan Dekuta Hotel Bali. Hal ini memiliki makna bahwa semakin rendah role stres yang dialamai karyawan Dekuta Hotel, maka akan semakin meningkatkan kepuasan kerja karyawan. Begitu pula sebaliknya, semakin tinggi role stres yang dirasakan karyawan Dekuta Hotel maka semakin kepuasan kerja karyawan pada Dekuta Hotel akan semakin menurun. 
Hasil tersebut mengindikasikan bahwa nilai - nilai yang terkandung dalam role stres mampu ditangani dengan baik dan berdampak nyata terhadap kepuasan kerja karyawan Dekuta Hotel. Role stres yang diukur berdasarkan indikator: beban kerja, tekanan dan konflik terbukti mampu mempengaruhi kepuasan kerja karyawan Dekuta Hotel. Temuan ini dapat diartikan bahwa apabila intensitas beban kerja, tekanan dan konflik kerja pada karyawan Dekuta Hotel dikurangi, maka akan mampu memberikan kontribusi yang signifikan untuk meningkatkan kepuasan kerja karyawan.

Penelitian ini sesuai dengan hasil penelitian Ang et al. (2014) yang menyatakan bahwa karyawan yang mengalami stress akan cenderung akan mengalami penurunan kepuasan kerja, dan sebaliknya karyawan yang memiliki stress rendah maka kepuasan kerja cenderung mengalami penurunan. Penurunan kepuasan kerja dapat dikaitkan dengan tingkat stress yang dialami oleh karyawan, karyawan yang mengalami stress dalam pekerjaannya cenderung memiliki kepuasan kerja yang turun (Muhammad et al., 2016). Hasil penelitian ini juga sesuai dengan temuan penelitian Yozgat et al., (2013), Damian (2016), dan Sari dkk. (2018) yang memperoleh hasil bahwa role stres berpengaruh negatif dan signifikan pada kepuasan kerja karyawan yang berarti semakin rendah tingkat stres karyawan maka akan berpengaruh pada semakin meningkatnya kepuasan kerja karyawan.

Berdasarkan hasil analisis pengaruh kompensasi finansial terhadap kepuasan kerja pada Tabel 12. diperoleh nilai signifikansi sebesar 0,019 dengan nilai koefisien regresi positif sebesar 0,354. Nilai signifikansi 0,019<0,05 mengindikasikan bahwa $\mathrm{H}_{0}$ ditolak dan $\mathrm{H}_{3}$ diterima. Hasil ini mempunyai arti bahwa kompensasi finansial berpengaruh positif dan signifikan terhadap kepuasan kerja karyawan Dekuta Hotel Bali. Hal ini memiliki makna bahwa semakin tinggi kompensasi finansial yang diberikan terhadap karyawan Dekuta Hotel, maka akan semakin tinggi pula kepuasan kerja yang ditunjukkan oleh karyawan. Begitu pula sebaliknya, semakin rendah kompensasi finansial yang diberikan kepada karyawan Dekuta Hotel maka semakin rendah tingkat kepuasan kerja karyawan pada organisasi tersebut.

Hasil tersebut mengindikasikan bahwa nilai - nilai yang terkandung dalam kompensasi finansial mampu dipersepsikan dengan baik dan berdampak nyata terhadap kepuasan kerja karyawan Dekuta Hotel. Kompensasi finansial yang diukur berdasarkan indikator: upah atau gaji, insentif, tunjangan dan fasilitas terbukti mampu meningkatkan kepuasan kerja karyawan Dekuta Hotel. Temuan ini dapat diartikan bahwa apabila jumlah upah atau gaji, insentif, tunjangan dan fasilitas di Dekuta Hotel ditingkatkan, maka akan mampu memberikan kontribusi yang signifikan untuk meningkatkan kepuasan kerja karyawan Dekuta Hotel.

Penelitian ini sesuai dengan hasil penelitian Wahyu (2017) menyatakan bahwa ada pengaruh yang kuat dari Kompensasi Finansial terhadap Kepuasan Kerja. Hal ini berarti jika Kompensasi Finansial semakin tinggi, maka akan berdampak pula pada semakin tingginya tingkat kepuasan kerja karyawan. Hasil penelitian ini juga sesuai dengan temuan penelitian Putri dkk. (2013), Dewi et al. (2013), Hidayat (2015), Ricky et al. (2016), Rachmandika dkk. (2016) dan Artha (2017) yang menyatakan bahwa semakin tinggi kompensasi financial yang 
diberikan kepada karyawan, maka kepuasan karyawan cenderung akan semakin meningkat.

Hasil penelitian menunjukkan bahwa lingkungan kerja, dan kompensasi finansial memberikan pengaruh yang positif dan signifikan terhadap kepuasan kerja karyawan, sedangkan role stres memberikan pengaruh yang negatif dan signifikan terhadap kepuasan kerja karyawan. Implikasi dari hasil penelitian yang didapat diharapkan mampu menjadikan tambahan pengetahuan, referensi dan bahan pertimbangan bagi pihak manajemen Dekuta Hotel dalam proses pengambilan keputusan dan penetapan kebijakan perusahaan untuk meningkatkan kepuasan kerja karyawannya.

Kondisi lingkungan kerja yang kondusif dan positif perlu ditingkatkan, sehingga kepuasan kerja karyawan akan meningkat. Selain itu, kompensasi finansial juga menjadi salah satu faktor yang sangat menentukan kepuasan kerja karyawan, karena dapat menjadi sumber motivasi karyawan untuk bekerja lebih baik bagi perusahaan. Kemudian role stres juga harus mampu diminimalisisr dengan baik, agar setiap pekerjaan dan tanggung jawab yang diberikan dapat dilaksanakan dengan baik dan tidak menjadi beban bagi karyawan. Jika lingkungan kerja, role stres dan kompensasi finansial ini mampu diterapkan dan dijalankan dengan baik, maka kepuasan kerja karyawan akan meningkat yang nantinya akan memberikan dampak yang sangat besar pada kinerja karyawan yang semakin membaik dan meningkat bagi Dekuta Hotel.

\section{SIMPULAN}

Simpulan dari penelitian ini yaitu pertama lingkungan kerja berpengaruh positif dan signifikan terhadap kepuasan kerja. Hal ini berarti bahwa semakin baik lingkungan kerja di Dekuta Hotel, maka akan semakin tinggi pula kepuasan kerja yang terbentuk pada karyawan. Kedua, role stres berpengaruh negatif dan signifikan terhadap kepuasan kerja. Hal ini berarti bahwa semakin rendah role stres yang dialami karyawan Dekuta Hotel, maka akan semakin meningkatkan kepuasan kerja karyawan. Ketiga, kompensasi finansial berpengaruh positif dan signifikan terhadap kepuasan kerja. Hal ini berarti bahwa semakin tinggi kompensasi finansial yang diberikan terhadap karyawan Dekuta Hotel, maka akan semakin tinggi pula kepuasan kerja yang ditunjukkan oleh karyawan.

Saran yang dapat diberikan berdasarkan hasil penelitian yaitu bagi HRD Dekuta Hotel sebaiknya mengevaluasi dan meningkatkan kembali fasilitas yang menunjang pekerjaan karyawan agar lingkungan kerja yang kondusif pada Dekuta Hotel dapat semakin meningkat. Kemudian pimpinan atau atasan Dekuta Hotel sebaiknya memberi tugas dan deadline kepada karyawan sesuai dengan kemampuannya agar karyawan tidak merasa tertekan dengan tugas dan deadline yang diberikan, sehingga role stress dapat diminimalisisr. HRD Dekuta Hotel juga disarankan dapat memberikan dukungan dan pengawasan yang baik kepada seluruh karyawan agar karyawan merasa diayomi, sehingga dapat meningkatkan kepuasan karyawan saat bekerja di Dekuta Hotel.

Saran bagi penelitian selanjutnya yaitu sebaiknya menambah variabel lain yang dapat mempengaruhi kepuasan kerja karyawan selain lingkungan kerja, role stres dan kompensasi finansial. Penelitian selanjutnya juga disarankan untuk 
memperluas wilayah penelitian agar hasil dalam penelitian dapat di generalisir pada seluruh Hotel di wilayah Kuta.

\section{REFERENSI}

Aghozo, G.K., I.S. Owusu, M.A. Hoedoafia, Y.B. Atakorah. 2017. The Effect of Work Environment on Job Satisfaction: Evidence from the Banking Sector in Ghana. Journal of Human Resource Management. 5(1), hal: 12-18.

Agnia, Riska. 2016. Pengaruh Kompensasi Dan Lingkungan Kerja Fisik Terhadap Kepuasan Kerja Karyawan Pada PT. Frigia Air Conditioning Bandung. Jurnal Fakultas Ekonomi dan Bisnis Unpas Bandung 25(1), hal: 159.

Annakis, John, Antonio Lobo and Soma Pillay. 2011. Exploring Monitoring, Work Environment And Flexibility As Predictors Of Job Satisfaction Within Australian Call Centres. International Journal of Business and Management.

Annakis, John, Antonio Lobo and Soma Pillay. 2011. Exploring Monitoring, Work Environment And Flexibility As Predictors Of Job Satisfaction Within Australian Call Centres. International Journal of Business and Management.

Aydogdu, Sinem and Baris Asikgil. 2012. An Empirical Study of the Relantionship Among Job Satisfaction, Organizational Commitment and Turnover Intention. International Review of Management and Marketing. 1(3), hal: 43-53.

Bhanu, M.V.V., dan P.C.S. Babu. 2018. Impact of Work Environment and Job Stress towards Job Satisfaction. IOSR Journal of Business and Management (IOSR-JBM). 20(2), hal: 01-07.

Sapriadi, D. (2013). Pengaruh Kualitas Pelayanan Pajak, Sanksi Pajak dan Kesadaran Wajin Pajak terhadap Kepatuhan Wajib Pajak dalam Membayar PBB (Pada Kecamatan Selupu Rejang), 1-27.

Bushra, Fatima, Ahmad Usman, Asvir Naveed. 2011. Effect of Transformational Leadership on Employees' Job Satisfaction and Organizational Commitment in Banking Sector of Lahore (Pakistan). International Journal of Business and Social Science. 2 (18), hal: 261-267.

Desiana, P.M. dan B.W. Soetjipto. 2006. Pengaruh Role Stressor, Persepsi Dukungan Organisasi terhadap Kepuasan Kerja dan Komitmen, Usahawan, No.05 Th. XXXV, hal: 22-32.

Dewi, A.A.U. 2014. Pengaruh Kompensasi dan Kepuasan kerja terhadap Komitmen Organisasi pada PT. Bali Marine Walk. E-Jurnal Manajemen Universitas Udayana, 3(11), hal: 3257-3273.

Elewa, E.S. 2017. Effects of Job Rotation and Role Stress on Job Satisfaction and 
Organizational Commitment among Large Scale of Administrative Staff in Nonprofit Organizations. Journal Research and Postgraduate Affairs Faculty of Commerce Master of Business \& Administration, hal: 1-15.

Erbasi, A., \& Arat, T. 2012. The Effect Of Financial and Non Financial Incentive On Job Satisfaction: An Examination of Food Chain Premises in Turkey. Journal International Business Research, hal: 136-145.

Fanani, Zaenal. 2008. Pengaruh Struktur Audit, Konflik Peran dan Ketidakjelasan Peran Terhadap Kinerja Auditor. Jurnal Akuntansi dan Keuangan Indonesia $5(2)$.

Hanna dan Firnanti. 2013. Pengaruh Struktur Audit, Komitmen Organisasi, Konflik Peran Dan Efektivitas Penggunaan Teknologi Sistem Informasi Akuntansi Terhadap Kinerja Auditor. Jurnal Bisnis dan Akuntansi. Vol 15, No. 1.

Hidayat, A. S. 2015. Pengaruh kompensasi dan pengembangan karir terhadap komitmen organisasi (studi kasus pada PT. Bank BRI Syariah Cabang Bandung Suniaraja). Jurnal Ecodemica, 3(1), hal: 334-341.

Hosein \& Amin. 2014. The Examination of the Role Conflict and Role Ambiguity on Job Satisfaction. Middle-East Journal Of Scientific Research. Vol. 20 (3), hal: $284-291$.

Husni., Said Musnadi, Faisal. 2018. Pengaruh Lingkungan Kerja, Kompensasi Dan Motivasi Terhadap Kepuasan Kerja Serta Dampaknya Terhadap Loyalitas Kerja Pegawai Rutan di Provinsi Aceh (Studi Kasus Pada Rutan Klas Iib Banda Aceh Dan Rutan Klas Ii B Jantho. Jurnal Magister Manajemen. 2(1), hal: 88-98.

Indah. 2013. Pengaruh Role Stressor Terhadap Komitmen Organisasi dengan Kepuasan Kerja sebagai Variabel Intervening. Jurnal Dinamika Akuntansi. 5(2), hal: 109-120.

Jorge , JD., Breikelen, GJP., Landerweerd, JA and Nijhuis , FJN (1999). ComparingGroup and Individual Level Assesment ofJob Characteristics In Testing The JobDemand-Control Model : A Multilevelapproach. Human Relation, hal: 122-195.

Mannasseh. 2014. Impact of Role Overload on Job Perfomance Among Cotruction Workers. Asian Journal of Social Sciences and Management Studies.1(3), hal: 83-86.

Nugroho, Agung Hery. 2006. Pengaruh konflik peran dan perilaku anggota organisasi terhadap kinerja kerja pegawai pada Kepolisian Republik Indonesia, Kepolisian Wilayah Kota Besar Semarang. 
eprints.undip.ac.id/.../AGUNG_HERY_NUGROH... diakses tgl. 5 Pebruari 2013, hal: 1-102.

Pangestu, Zulfahmi Septian., Mochammad Djudi Mukzam dan Ika Ruhana. 2017. Pengaruh Lingkungan Kerja Terhadap Kepuasan Kerja (Studi pada Karyawan Perum Perhutani Ngawi). Jurnal Administrasi Bisnis (JAB). 43(1), hal: 157-162.

Putri, Sari Dewi. 2016. Pengaruh Lingkungan Kerja Terhadap Kepuasan Kerja Karyawan Hotel Grand Rocky Bukittinggi. E-Journal Home Economic and Tourism. 13(3), hal: 1-17.

Quaarat. Muhammad. \& Nadeem. 2013. Impact of Role Conflict on Job Satisfaction, Mediating Role of Job Stress in Private Banking Sector. Interdiscliplinary Journal of Contemporary Research In Business. 4(12), hal: 711-722.

Rachmandika, Iman., Mochammad Al Musadieq dan Yuniadi Mayowan. 2015. Pengaruh Kompensasi Finansial Dan Kompensasi Non Finansial Terhadap Kepuasan Kerja Karyawan (Studi pada Karyawan PT Semen Indonesia (Persero) Tbk). Jurnal Administrasi Bisnis (JAB), 33(1), hal: 9-17

Robbins, Stephen P. dan Timothy A. Judge. 2008. Perilaku Organisasi (Organizational Behavior). Jilid 1, edisi 12. Jakarta: Penerbit Salemba Empat.

Ruchi \& Surinder. 2014. Impact Of Work Environment On Job Satisfaction. International Journal of Scientific and Research. 4, hal: 2250-3153.

Santoso, Desyeani Oktavia. 2015. Pengaruh Kompensasi Finansial Dan Non Finansial Terhadap Kepuasan Kerja Karyawan Akor Global. Jurnal AGORA 3(1), hal: 56- 61.

Santoso, Agus. 2018. Pengaruh Efikasi Diri, Motivasi Kerja, Dan Lingkungan Kerja Terhadap Kepuasan Kerja Pegawai Pt. Sukanda Djaya Cabang Denpasar. Skripsi. Fakultas Ekonomi Universitas Udayana.

Sari, Dewi Puranama. 2018. Pengaruh Lingkungan Kerja Dan Disiplin Kerja Terhadap Kepuasan Kerja Guru Sekolah Menengah Kejuruan (SMK) Swasta Sekecamatan Pondok Aren. Jurnal Saintika Unpam.1(1), hal: 108132.

Sari, Nur Rahmah., Memen Suwandi, dan Andi Nurul Izmi Amalia. 2018. Pengaruh Role Stress Dan Emotional Intelligence Terhadap Kinerja Auditor dengan Aspek Psycological Well-Being Sebagai Pemoderasi. Jurnal Ilmiah Akuntansi Peradaban. 4(1), Hal: 49-69. 
Schubroeck, J and Fink, LS. 1998. Facilitating And Inhibiting Effects Of JobControl And Social Support On StressOutcomes And Role Behavior : AContingency Mode", Journal of Organizational Behavior , p:167-195.

Setyani, Tri Budi. 2014. Analisis Pengaruh Kompensasi, Motivasi, Lingkungan Kerja, Dan Budaya Organisasi Terhadap Kinerja Karyawan (Studi Kasus di Lingkungan Pegawai Kantor PDAM Boyolali). Naskah Publikasi. Fakultas Ekonomi Dan Bisnis Universitas Muhammadiyah Surakarta.

Sormin, T.R., H.U. Anisah dan M.S. Dewi. 2017. Pengaruh Stres Kerja Terhadap Kepuasan Kerja Serta Dampaknya Terhadap Kinerja Karyawan Pada Karyawan Di Pt Panin Bank Banjarmasin. Jurnal Wawasan Manajemen. 5(1): 63-72.

Sugiyono. 2013. Metode Penelitian Bisnis. Bandung: Alfabeta.

Wahyu, Ellyn Eka. 2017. Pengaruh Kompensasi Finansial Dan Kompensasi Non Finansial Terhadap Kepuasan Kerja Karyawan Pada Sweet Garden Guest House Malang. Jurnal Administrasi dan Bisnis, 11(2).

Wirawan, I Dewa Gede Kresna., dan I Nyoman Sudharma. 2015. Pengaruh Komunikasi, Motivasi dan Lingkungan, Kerja Fisik Terhadap Kepuasan Kerja Pegawai Sekretariat Daerah Kota Denpasar. E-Jurnal Manajemen Unud. 4(10), hal: 3037-3062.

Yozgat, Ugur. Assoc. Serra Yurtkoru, Elif Bilginoglu. 2013. Job stres and job performance among employes in public sector in Istanbul: examining the moderating role of emotional intelligence. Social and Behavior Sciences, (75), hal: 518-524. 